\title{
Uso terapêutico de tecidos e órgãos humanos para transplantes: eventos adversos e ações de biovigilância
}

\author{
Therapeutic use of human tissues and organs for transplants: adverse events and biovigilance \\ actions
}

\section{Uso terapéutico de tejidos y órganos humanos para trasplantes: eventos adversos y acciones de biovigilancia}

\section{RESUMO}

Objetivo: Identificar evidências na literatura sobre eventos adversos e ações de biovigilância no processo de doação e uso terapêutico de tecidos e órgãos humanos para transplante. Método: Revisão integrativa, utilizando as bases de dados LILACS, MEDLINE e Embase. Critérios de inclusão: estudos primários em inglês, espanhol e português, publicados entre 2015 a 2021, acerca da biovigilância na doação e transplante, riscos e eventos adversos. Resultados: Analisados 10 artigos, identificando a ocorrência de eventos adversos referentes ao processo de doação e transplante e estratégias de biovigilância para reduzir riscos e aumentar a segurança. Conclusão: Riscos e eventos adversos podem ocorrer no processo de doação e transplante. Observaram-se estratégias, para mitigar os riscos e a ocorrência/recorrência de eventos adversos, propiciando maior qualidade assistencial e segurança ao paciente. O enfermeiro tem papel fundamental no que concerne à biovigilância, estando presente em todas as fases do processo de doação e transplante.

Descritores: Biovigilância; Segurança do Paciente; Efeitos Colaterais e Reações Adversas Relacionados a Medicamentos; Obtenção de Tecidos e Órgãos; Transplante.

\section{ABSTRACT}

Purpose: To identify evidence in the literature regarding adverse events and biovigilance actions in the process of donation and therapeutic use of human tissues and organs for transplantation. Method: An integrative review consulting the following databases: LILACS, MEDLINE, and Embase. Inclusion criteria: Primary studies in English, Spanish and Portuguese, published between 2015 and 2021, about biovigilance in the donation and transplants, risks, and adverse events. Results: 10 articles were analyzed, identifying the occurrence of adverse events related to the process of the donation and transplants, biovigilance strategies aiming to reduce risk and increase safety. Conclusion: Risks and adverse events can occur in the process of donation and transplantation. Estrategies were observed to mitigate the risks and occurrence/recurrence of adverse events, providing assistance with greater quality and patient safety. Nurses have a fundamental role with regard to biosurveillance, as they are present in all stages of the donation and transplants. Descriptors: Biosurveillance; Patient Safety; Drug-Related Side Effects and Adverse Reactions; Tissue and Organ Procurement; Transplantation.

\section{RESUMEN}

Objetivo: Identificar evidencias en la literatura sobre efectos adversos y acciones de biovigilancia en el proceso de donación y uso terapéutico de tejidos y órganos humanos para trasplante. Método: Revisión integradora, utilizando las bases de datos LILACS, MEDLINE y Embase. Criterios de inclusión: estudios primarios en inglés, español y portugués, publicados en 2015-2021, sobre biovigilancia en donación y trasplantes, riesgos y eventos adversos. Resultados: Se analizaron 10 artículos, se identificó la ocurrencia de efectos adversos referentes al proceso de donación y trasplante, estrategias de biovigilancia para reducir riesgos y aumentar la seguridad. Conclusión: Riesgos y efectos adversos pueden ocurrir en el proceso de donación y trasplante. Estrategias para mitigar los riesgos y la ocurrencia/recurrencia de efectos adversos, propician asistencia de mayor calidad y seguridad para el paciente. El enfermero tiene un papel fundamental en la biovigilancia, ya que está presente en todas las etapas del proceso de donación y trasplante.

Descriptores: Biovigilancia; Seguridad del Paciente; Efectos Colaterales y Reacciones Adversas Relacionados con Medicamentos; Obtención de Tejidos y Órganos; Trasplante.
Patricia Treviso ${ }^{1}$

$\underline{0000-0002-5015-6797}$

Janine Schirmer ${ }^{2}$

$\underline{0000-0003-0783-2961}$

Karina Dal Sasso Mendes ${ }^{2}$

0000-0003-3349-2075

Sabrina Alves Fernandes ${ }^{3}$ 0000-0001-8504-603X

Andresa Thomé Silveira ${ }^{4}$ D. 0000-0002-9347-7531

Bartira de Aguiar Roza²

D 0000-0002-6445-6846

1 Universidade do Vale dos Sinos, RS, Brasil.

2 Universidade de São Paulo, SP, Brasil.

${ }^{3}$ Centro Universitário Metodista IPA, RS, Brasil.

4 Universidade Federal de Ciências da Saúde de Porto Alegre, RS, Brasil.

Autor correspondente: Patrícia Treviso E-mail: ptreviso15@gmail.com

Como citar este artigo:
Treviso P, Schirmer J, Mendes KDS, et
al. Uso terapêutico de tecidos e órgãos
humanos para transplantes: eventos
adversos e ações de biovigilância.
Revista de Enfermagem do Centro-
Oeste_ Mineiro. 2021;11:e4044.
[Access__]; Available in:
DOI:
http://dx.doi.org/10.19175/recom.v11i
0.4044




\section{INTRODUÇÃO}

Nos diferentes cenários de cuidado à saúde humana, a qualidade e a segurança têm sido foco de atenção, estudo e discussão, não sendo diferente na área de doação e transplante de órgãos e tecidos, área que vem crescendo, em diversos países, assim como no Brasil, que possui um dos maiores programas públicos de transplantes. Nas duas últimas décadas, a Organização Mundial de Saúde (OMS) tem trabalhado fortemente em ações e estratégias, em parceria com os países membros, objetivando reduzir riscos e a ocorrência de incidentes e eventos adversos ${ }^{(1-2)}$.

O conceito de incidentes é descrito na literatura como eventos ou circunstâncias que resultaram ou poderiam ter resultado em dano desnecessário ao paciente, enquanto risco é definido como a probabilidade de o incidente ocorrer $^{(1)}$. O incidente ainda pode ser definido como quase erro (near miss), evento adverso ou evento sentinela. $O$ quase erro é o incidente que não atingiu o paciente, mas chegou perto de ocorrer; o evento adverso é o incidente que resultou em dano ao paciente; enquanto o evento sentinela é a situação em que o dano causou sequelas irreversíveis ou mesmo o óbito do paciente $^{(1)}$.

Em relação ao processo de doação e transplante de órgãos e tecidos, a Agência Nacional de Vigilância Sanitária (Anvisa) define evento adverso e incidente ${ }^{(3)}$ :

Evento Adverso: Qualquer ocorrência desfavorável relacionada à doação, retirada/coleta, avaliação, processamento, armazenamento, distribuição e ao procedimento de uso terapêutico de células, tecidos e órgãos, em um receptor ou doador vivo, podendo ou não levar à transmissão de uma enfermidade, morte, risco à vida, deficiências ou incapacidades ou hospitalização ou, ainda, a prolongação do tempo de enfermidades ou hospitalização. Incidente: Ocorrência de desvio dos procedimentos operacionais ou das políticas de segurança do indivíduo no estabelecimento de saúde relacionada à doação, coleta/retirada, avaliação, processamento, armazenamento e distribuição de células, tecidos e órgãos detectados durante ou após a doação ou o transplante/infusão/enxerto/implante que podem ou não levar à transmissão de uma enfermidade, morte, risco à vida, deficiências ou incapacidades ou hospitalização ou, ainda, a prolongação do tempo de enfermidades ou hospitalização, em um receptor ou doador vivo ${ }^{(3)}$.

Em todas as fases do processo de doação e uso terapêutico de órgãos e tecidos, o risco está presente tanto na doação intervivos quanto na doação com doador falecido, podendo envolver tanto o doador como o receptor ${ }^{(3)}$. Embora o transplante possa trazer benefícios para os receptores, o risco deve ser sempre considerado, visto que o processo pode envolver a transmissão de doenças, infecções, neoplasias ou mesmo acarretar outras complicações ${ }^{(3-4)}$.

A segurança, portanto está relacionada com todas as etapas do processo de doação e uso terapêutico de órgãos e tecidos, que devem ser conduzidas e documentadas de acordo com o que rege a legislação. A segurança é considerada uma das dimensões da qualidade, e analisar de forma sistemática os riscos e a ocorrência de eventos adversos possibilita identificar, prevenir e mitigar danos e melhorar processos ${ }^{(5-7)}$. A utilização de indicadores também pode auxiliar no acompanhamento e no controle do processo de transplantes, sendo a ferramenta que possibilita mensurar os processos ${ }^{(8)}$. Nesse contexto, ressalta-se que a doação de órgãos também depende da confiança no sistema e na segurança do processo e que falhas podem resultar em agravos ao paciente e repercussões danosas à sociedade e equipes de saúde ${ }^{(9)}$.

Desenvolver os procedimentos com qualidade e segurança é um desafio para os sistemas de vigilância, para as instituições e para os profissionais de saúde. No contexto da doação e transplante, faz-se necessário realizar o gerenciamento de riscos, por meio da biovigilância, implantando e desenvolvendo ações que possibilitem monitorar todo o macroprocesso ${ }^{(3)}$. Nesse sentido, biovigilância é definida como um conjunto de ações de monitoramento e controle que abrange o ciclo do uso terapêutico de células, tecidos e órgãos humanos, desde a doação até a evolução clínica do receptor, visando obter informações sobre riscos e eventos adversos, prevenindo sua ocorrência ou recorrência ${ }^{(3)}$.

O processo de doação e uso terapêutico de tecidos e órgãos humanos para transplantes tem significativa relevância social em virtude dos benefícios dessa terapêutica. Entretanto trata-se de processo complexo e que envolve elevado número de profissionais de diferentes áreas, desde a doação até o acompanhamento do 
receptor após o transplante, sendo permeado por riscos. Diante desse cenário, justifica-se a realização deste estudo.

O presente estudo tem como objetivo identificar evidências na literatura sobre eventos adversos e ações de biovigilância no processo de doação e uso terapêutico de tecidos e órgãos humanos para transplante.

\section{MÉTODO}

A pesquisa é do tipo revisão integrativa, método que tem por finalidade reunir e sintetizar o resultado de pesquisas sobre um delimitado tema de maneira sistemática e ordenada, sendo instrumento para o aprofundamento do conhecimento a respeito do tema investigado, permitindo a síntese de estudos publicados e conclusões gerais de uma particular área de estudo(10). Seguindo o referencial teórico de Mendes, Silveira e Galvão(10), a revisão integrativa compreende seis etapas, a saber: identificação do tema e seleção da pergunta de pesquisa, estabelecimento dos critérios para a seleção da amostra, definição das informações a serem extraídas dos artigos selecionados, análise dos resultados, apresentação e síntese do conhecimento ${ }^{(10)}$.

A pergunta de pesquisa foi elaborada, de acordo com a estratégia PICO, acrônimo de Patient or Problem, Intervention, Comparison e Outcomes. Dessa forma, delimitou-se a seguinte questão: quais são as evidências na literatura sobre eventos adversos e ações de biovigilância no processo de doação e uso terapêutico de tecidos e órgãos humanos para transplante? Assim: $(P)$ se refere ao processo de doação e uso terapêutico de tecidos e órgãos humanos; o (I) a ações de biovigilância; e o (O) a eventos adversos. Neste caso, não se utilizou o (C) de comparação.

Os critérios de inclusão foram: estudos primários publicados em inglês, espanhol e português, publicados no período de 2015 a 2021 (o período maior que cinco anos se deu pela escassez de publicações na temática), disponíveis na íntegra e artigos com informações sobre biovigilância no processo de doação e uso terapêutico de tecidos e órgãos humanos para transplantes, seus riscos e eventos adversos.

Os artigos foram identificados por busca na literatura, realizada em fevereiro de 2021, nas bases de dados: Medical Literature Analysis and Retrieval System Online (MEDLINE), consultada por meio do PubMed; Literatura Latino-americana e do Caribe em Ciências da Saúde (LILACS), consultada pela Biblioteca Virtual em Saúde (BVS); e Embase. As estratégias de busca foram realizadas, com base nos Descritores em Ciências da Saúde (DeCS): "Biovigilância"; "Segurança do Paciente"; "Efeitos Colaterais e Reações Adversas Relacionados a Medicamentos"; "Obtenção de Tecidos e Órgãos"; "Transplante.

Na sequência, foi realizada a exclusão das duplicidades entre as diferentes bases de dados. Logo após, foi feita a leitura dos títulos e resumos, com a exclusão dos estudos que não atendiam aos critérios de inclusão ou ao tema proposto. Foram selecionados 39 artigos para a próxima fase, ou seja, leitura na íntegra, que foi realizada por dois avaliadores independentes (com experiência no tema investigado), visando favorecer a validação da seleção dos artigos para a análise. Para esta análise, os avaliadores consideraram os critérios de inclusão e exclusão e a questão de pesquisa, resultando em 10 artigos, os quais constituíram a amostra final desta revisão (Figura 1).

Figura 1 - Fluxo do processo de seleção dos estudos para a revisão integrativa

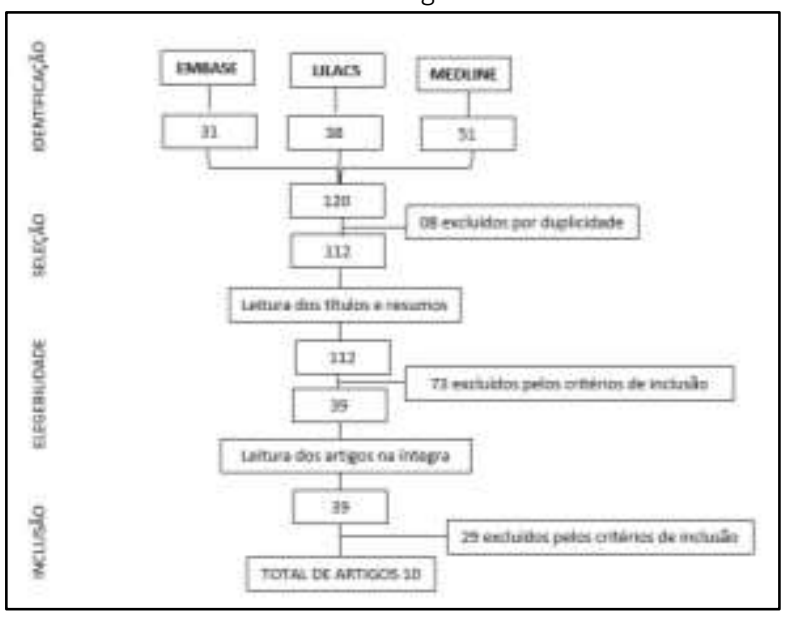

Fonte: Dados do estudo.

As publicações selecionadas, para a amostra final, foram analisadas, interpretadas de forma organizada e sintetizadas por meio da elaboração de um quadro sinóptico. A qualidade dos estudos foi avaliada, com base na classificação do nível de evidência, de acordo com o Centro de Medicina Baseada em Evidências de Oxford ${ }^{(11)}$, que classifica os estudos em cinco níveis: I revisão sistemática ou ensaios randomizados; II pesquisa randomizada; III - estudos de coorte/acompanhamento não randomizado; IV estudos de caso ou caso-controle; $V$ - opinião de especialistas ou com base em normas e legislação. 
Os dados foram analisados sob a ótica da análise temática, sendo elencadas três categorias: "Processo de doação e transplante de órgãos", "Segurança do paciente: equipe multidisciplinar, processos e transição do cuidado" e "Biovigilância".

A apresentação dos resultados e a discussão dos dados obtidos foi feita de forma descritiva, possibilitando conhecer os dados relacionados aos eventos adversos e à biovigilância no processo de doação e uso terapêutico de tecidos e órgãos humanos para transplante evidenciados na literatura.

\section{RESULTADOS E DISCUSSÃO}

Foram selecionados 10 artigos que atendiam aos critérios de inclusão para o alcance do objetivo proposto. O maior número de publicações foi apurado na base de dados LILACS (50\%), com predomínio do idioma inglês (90\%) e datas de publicação entre 2015 e 2018, sendo maioria (40\%) de 2016; no entanto não foram incluídos artigos publicados em 2019, 2020 e 2021, visto não atenderem aos critérios delimitados pelo estudo. Na amostra selecionada, houve predominância de estudos realizados no Brasil (50\%) e de estudos com nível de evidência IV (50\%). A apresentação da síntese dos artigos incluídos neste estudo encontra-se no Quadro 1.

Quadro 1 - Síntese dos artigos incluídos no estudo

\begin{tabular}{|c|c|c|c|c|c|}
\hline Referência & $\begin{array}{l}\text { Ano } \\
\text { País }\end{array}$ & $\begin{array}{c}\text { Delineamento } \\
\text { Amostra }\end{array}$ & Intervenções & Desfechos & $\begin{array}{l}\text { Nível de } \\
\text { evidência }\end{array}$ \\
\hline $\begin{array}{l}\text { Pontes et al. } \\
(2018)^{(12)}\end{array}$ & $\begin{array}{l}2018 \\
\text { Brasil }\end{array}$ & $\begin{array}{l}\text { Estudo } \\
\text { descritivo, } \\
\text { retrospectivo, } \\
\text { qualitativo. } \\
\text { n=1.090 }\end{array}$ & $\begin{array}{l}\text { Análise de notificações de } \\
\text { incidentes. }\end{array}$ & $\begin{array}{c}\text { Todos os incidentes geraram dano aos } \\
\text { pacientes, de maior ou menor grau, } \\
\text { nas dimensões de dano físico e danos } \\
\text { subjetivos. }\end{array}$ & IV \\
\hline $\begin{array}{l}\text { Grossi et al. } \\
(2018)^{(13)}\end{array}$ & $\begin{array}{l}2018 \\
\text { Itália }\end{array}$ & $\begin{array}{l}\text { Estudo de } \\
\text { coorte } \\
\text { retrospectiva. } \\
n=260\end{array}$ & $\begin{array}{c}\text { Análise de doadores com } \\
\text { risco de infecção por HCV, } \\
\text { HBV e HIV e } \\
\text { acompanhamento dos } \\
\text { receptores. }\end{array}$ & $\begin{array}{l}\text { Há risco de transmissibilidade de HCV } \\
\text { e HIV na doação e transplante de } \\
\text { órgãos. Existe risco do período de } \\
\text { janela de transmissão. A transmissão } \\
\text { de HBV e HCV acometeu } 12,6 \% \text { dos } \\
\text { pacientes acompanhados neste } \\
\text { estudo. Não houve casos de } \\
\text { transmissão de HIV. }\end{array}$ & III \\
\hline $\begin{array}{l}\text { Rosa et al. } \\
(2017)^{(14)}\end{array}$ & $\begin{array}{l}2017 \\
\text { Brasil }\end{array}$ & $\begin{array}{c}\text { Estudo } \\
\text { quantitativo, } \\
\text { transversal. } \\
\mathrm{n}=60\end{array}$ & $\begin{array}{l}\text { Aplicação de questionário } \\
\text { sobre segurança no processo } \\
\text { de doação de córnea. }\end{array}$ & $\begin{array}{l}\text { Maior parte dos participantes } \\
\text { sentem-se seguros quanto ao } \\
\text { processo de segurança na doação. }\end{array}$ & IV \\
\hline $\begin{array}{l}\text { Cristelli et al. } \\
(2016)^{(15)}\end{array}$ & $\begin{array}{l}2016 \\
\text { Brasil }\end{array}$ & $\begin{array}{l}\text { Estudo clínico, } \\
\text { prospectivo. } \\
\text { n=39 }\end{array}$ & $\begin{array}{l}\text { Análise de tratamento } \\
\text { medicamentoso em } \\
\text { pacientes pós-transplante } \\
\text { renal. }\end{array}$ & $\begin{array}{l}\text { Eventos adversos relacionados ao } \\
\text { tratamento: úlceras orais, } \\
\text { dislipidemia, edema periférico. }\end{array}$ & 1 \\
\hline $\begin{array}{l}\text { Lima et al. } \\
(2016)^{(16)}\end{array}$ & $\begin{array}{l}2016 \\
\text { Brasil }\end{array}$ & $\begin{array}{c}\text { Estudo } \\
\text { quantitativo, } \\
\text { transversal. } \\
\mathrm{n}=74\end{array}$ & $\begin{array}{l}\text { Análise de fragilidades } \\
\text { relacionadas ao tratamento } \\
\text { medicamentoso na alta } \\
\text { hospitalar de pacientes } \\
\text { transplantados. }\end{array}$ & $\begin{array}{l}\text { Maior parte das fragilidades estavam } \\
\text { relacionadas à não prescrição do } \\
\text { medicamento necessário. }\end{array}$ & IV \\
\hline $\begin{array}{l}\text { Meng, Yang e } \\
\text { Yan (2016) }\end{array}$ & $\begin{array}{l}2016 \\
\text { China }\end{array}$ & $\begin{array}{c}\text { Estudo } \\
\text { quantitativo } \\
\text { retrospectivo. } \\
n=356\end{array}$ & $\begin{array}{l}\text { Análise de complicações pós- } \\
\text { operatórias em doadores } \\
\text { vivos de fígado. }\end{array}$ & $\begin{array}{l}\text { Maior parte das complicações são } \\
\text { relacionadas a complicações biliares. } \\
\text { Gravidade mínima. }\end{array}$ & IV \\
\hline $\begin{array}{l}\text { Ribeiro et al. } \\
(2016)^{(18)}\end{array}$ & $\begin{array}{l}2016 \\
\text { Brasil }\end{array}$ & $\begin{array}{l}\text { Estudo de } \\
\text { coorte, } \\
\text { retrospectivo. } \\
n=446\end{array}$ & $\begin{array}{l}\text { Grupo controle e grupo teste } \\
\text { para avaliar os desfechos do } \\
\text { transplante renal com } \\
\text { doador falecido em } \\
\text { receptores sensibilizados } \\
\text { sem a prévia identificação da } \\
\text { presença de anticorpos anti- } \\
\text { HLA específicos contra o } \\
\text { doador. }\end{array}$ & $\begin{array}{l}\text { Indivíduos sensibilizados } \\
\text { apresentaram maior incidência de } \\
\text { infecção. Não houve diferença nas } \\
\text { sobrevidas do enxerto e paciente. }\end{array}$ & III \\
\hline
\end{tabular}


entre outros, são fatores que podem interferir na segurança do paciente ${ }^{(21)}$.

Nesse cenário, o paciente transplantado é vulnerável à ocorrência de incidentes e/ou eventos adversos, tais como infecções (bacterianas, fúngicas ou virais)(12,14,18-19,21), reações adversas relacionadas à administração de medicamentos ${ }^{(15-16,21)}$, reações infusionais ${ }^{(21)}$, complicações cirúrgicas ${ }^{(15,17)}$, rejeição do órgão(15,18) e óbito ${ }^{(18,21)}$. O risco de transmissão de doenças pelo órgão e/ou tecido transplantado existe, e as complicações podem impactar na função do órgão enxertado, na qualidade de vida e na sobrevida do indivíduo transplantado ${ }^{(22)}$. Vale destacar que a imunossupressão também é um fator que contribui para o advento de infecções e que nem sempre está relacionada a eventos adversos, mas em decorrência da situação de imunossupressão(23).

Em um cenário em que há carência de doadores $^{(17)}$ e um número crescente de doentes, ingressando em lista de espera para o transplante, pensar a segurança tanto do doador como do receptor é imperativo e, portanto definir e seguir critérios de segurança são de grande relevância. A avaliação criteriosa dos doadores e dos órgãos e tecidos, como a viabilidade, o tamanho, possíveis lesões, entre outros, são fundamentais para a segurança do paciente ${ }^{(17)}$. Destaca-se que, na doação intervivos, a segurança é ainda de maior relevância, visto que o doador é um indivíduo saudável que, de forma alguma, deveria sofrer danos relativos à doação(17).

Há situações que evidenciam que a evolução do conhecimento científico e a inserção de novas tecnologias proporcionam mudanças no cuidado à saúde pela qualidade, agilidade e precisão. No entanto a complexidade dos procedimentos e tratamentos pode implicar a ocorrência de danos relacionados à assistência, exigindo da equipe assistencial conhecimento técnico e científico para a prestação de cuidados com qualidade e segurança ${ }^{(12-13)}$. Os eventos que afetam ou têm o potencial de afetar a segurança do paciente podem ter como causas erro humano, falhas de processo, falhas de comunicação, entre outras ${ }^{(20-21)}$.

\section{Segurança do paciente: equipe multidisciplinar, processos e transição do cuidado}

O trabalho multidisciplinar, a dinâmica e a interação entre os profissionais e as diferentes equipes é de extrema relevância à continuidade do cuidado ao paciente, assim como para a segurança do cuidado a ser prestado(16). Lembrando que todos estão a serviço do paciente, devendo a qualidade e a segurança da assistência ser um objetivo de todos. Profissionais com comportamento não agregador podem interferir de forma negativa na interação e na comunicação entre a equipe, comprometendo a segurança do paciente. A atuação da equipe multidisciplinar engajada na assistência segura é fator crucial para a segurança do paciente ${ }^{(16)}$.

Nesse contexto, o enfermeiro atua, em todo o percurso do processo de doação e transplante de órgãos e tecidos, realizando atividades assistenciais e gerenciais. A magnitude e a complexidade do cuidado prestado pelo enfermeiro, nas distintas fases do processo, exigem formação qualificada, capacitações e vigilância constante, visando à segurança do paciente e também dos profissionais envolvidos.

Estudos apontam que falhas nos processos ou na comunicação entre profissionais e diferentes equipes estão intrinsecamente envolvidas em eventos adversos evitáveis ${ }^{(14,20)}$, implicando atraso de resultados de análises laboratoriais e erros de acondicionamento, transporte e rotulagem do órgão/tecido, o que pode resultar em descarte do órgão doado ou em complicações ao paciente transplantado(20). Destaca-se, ainda, como causas de eventos adversos, a falta de conhecimento ou o não seguimento de rotinas e protocolos préestabelecidos ${ }^{(14,20)}$, a falta de equipamentos ou materiais necessários para a assistência, seja ela clínica, cirúrgica, hospitalar ou ambulatorial, o atraso de informações essenciais ao processo de doação e transplante, como resultados de análises laboratoriais, entre outros ${ }^{(14,20)}$.

Outro fator-chave na qualidade e segurança assistencial é o conhecimento e domínio das evidências científicas, dos protocolos e das rotinas institucionais ${ }^{(14)}$. Entretanto estudos apontam que ainda há lacunas na formação de profissionais da saúde e que a falta de capacitação e conhecimento pode colocar em risco tanto a doação como o aproveitamento dos órgãos e tecidos doados ${ }^{(14)}$. Essas situações podem ser consideradas eventos adversos evitáveis ou mesmo quase erros ${ }^{(20)}$.

Equipes de saúde altamente capacitadas são o ponto-chave para o sucesso da doação e do transplante ${ }^{(14)}$. Em estudo realizado com profissionais médicos, em relação à segurança no 
processo de doação de córneas, $68 \%$ apontaram possuir segurança no processo, enquanto $31 \%$ revelaram não ter segurança para essa condição, tendo como justificativa a pouca informação a respeito, o pouco contato com potenciais doadores e o desinteresse pelo assunto. Os autores apontam que a tendência de estabilização ou mesmo a diminuição de doações podem ser um reflexo do despreparo de profissionais em identificar potenciais doadores e em abordar a família do potencial doador ${ }^{(14)}$.

Tanto o potencial doador como a pessoa recém-transplantada são, de modo geral, pacientes críticos que demandam cuidados múltiplos, devendo ser garantida a segurança e a qualidade na prestação da assistência, como, entre tantos outros cuidados, na manipulação de cateteres, na administração de medicamentos e na avaliação criteriosa do paciente, mitigando os riscos de incidentes ${ }^{(12)}$.

Nesse contexto, diversos cuidados exigem a interação e o trabalho interdisciplinar, como os cuidados relacionados ao tratamento medicamentoso, às mudanças no estilo de vida do paciente e sua adesão às orientações quanto ao autocuidado e ao preparo para a alta hospitalar. Nesses cuidados, a abordagem interdisciplinar pode inferir maior segurança ao paciente, envolvendo não apenas o profissional médico e enfermeiro, como também o farmacêutico, o nutricionista, o psicólogo, o assistente social e o fisioterapeuta ${ }^{(16)}$. Vale ressaltar que cada profissão tem seu conhecimento específico, e todas são importantes e complementares na prestação do cuidado. Pensar em ações educativas, envolvendo atuação e articulação interprofissional, pode trazer resultados mais eficazes no cuidado ao paciente.

Processos falhos também são computados, como causa de eventos adversos ${ }^{(20)}$, assim como fragilidades na estrutura das instituições, podendo ter impacto negativo e afetar a assistência ao paciente. Em estudo que analisou 438 eventos adversos, referentes ao processo de doação e transplante, os resultados apontam que $44 \%$ das situações que envolveram falhas na segurança do paciente estavam relacionadas a falhas nos processos institucionais, ou a falhas de comunicação e, em algumas situações, tais falhas resultaram em perda/descarte de órgãos viáveis para transplante ${ }^{(20)}$. Como exemplos, destacamse: a troca de lateralidade; o erro de rotulagem do recipiente contendo o órgão; o aumento do tempo de isquemia fria, ultrapassando o limite máximo; a violação de esterilidade; o congelamento do órgão; o dano nos vasos ou na estrutura do órgão durante o procedimento de retirada; ou o preparo do órgão para a enxertia ${ }^{(20)}$.

Outros aspectos ainda podem afetar a segurança dos processos assistenciais, como: insuficiência de materiais e equipamentos necessários à assistência; falha na realização de exames e procedimentos; falhas no acondicionamento e/ou transporte de órgãos e tecidos; instrumental cirúrgico insuficiente ou em más condições; controle inadequado de instrumental cirúrgico, com risco de retenção de objetos intracavitários; escassez de leitos de terapia intensiva e de unidade de internação; falha na passagem de plantão ou transferência do paciente (transição do cuidado) ${ }^{(16,20)}$.

A questão da segurança do paciente assume especial importância, em situações de transição do cuidado, como na transferência do paciente para outras unidades ou instituições e mesmo na alta hospitalar ${ }^{(16)}$. A comunicação nesse processo é fator crucial para a segurança ${ }^{(16,20)}$. A transferência do paciente de uma unidade para outra exige comunicação clara e troca de informações entre os profissionais de saúde. Quem transfere o paciente deve informar aos profissionais da unidade receptora informações sobre o estado do paciente - condições clínicas, riscos, intercorrências, cuidados prestados, entre outros -, possibilitando, assim, a continuidade da assistência com segurança. A transição do cuidado é um processo que se destaca na atuação da equipe de enfermagem pela dinâmica própria dessa profissão, presente 24 horas na assistência direta e contínua ao paciente.

Uma questão que se destaca, nos processos de transição de cuidados ou mesmo de alta hospitalar, é a farmacoterapia, levando em consideração que o uso de medicamentos por esses pacientes é complexo, aumentando o risco de erros na administração de medicamentos, mediante o não entendimento de orientações por parte do paciente e/ou da família, ou, ainda, pela transferência incorreta ou incompleta de informações entre profissionais ou desses para o paciente, além de envolver múltiplas ações, como a atuação multiprofissional e interinstitucional ${ }^{(16)}$. Uma estratégia, para facilitar o entendimento do paciente quanto ao tratamento medicamentoso é, além da orientação verbal e escrita, fazer uso de instrumentos que possibilitem o contato direto 
com o paciente e facilitem seu entendimento, como o uso de símbolos, cores e/ou figuras que possam ilustrar o que está descrito na prescrição médica ${ }^{(16)}$.

Os eventos adversos decorrentes do tratamento medicamentoso podem estar relacionados a diversos fatores, como a não prescrição do medicamento necessário ao paciente, a administração de subdose ou sobredose, a indisponibilidade do medicamento na rede de acesso, a prescrição com redação incorreta ou ilegível, a seleção inadequada do medicamento, o não cumprimento do horário/intervalo de administração do medicamento, a não adesão, entre outros ${ }^{(16)}$.

O evento adverso pode ocorrer, não só durante a internação do paciente, mas também após a alta ${ }^{(16)}$. Estratégias como o ensino ao paciente e familiar/cuidador, quanto a sinais e sintomas de alterações ou complicações, podem ser úteis na prevenção de danos ${ }^{(16)}$. As complicações decorrentes dos eventos adversos implicam, ainda, custo adicional às instituições de saúde ${ }^{(12)}$, em decorrência da necessidade de ampliação do tempo de hospitalização ou de reinternações ${ }^{(12,18)}$ e da realização de procedimentos (invasivos ou não) que não seriam necessários, caso o evento adverso não tivesse ocorrido - como exames laboratoriais ou de imagem - ou mesmo a mitigação dos danos ${ }^{(12)}$.

Torna-se evidente o dano que falhas em processos e estruturas causam na assistência, na qualidade, na segurança e nos resultados. De acordo com a literatura, incidentes e eventos adversos relacionados aos cuidados na doação e transplante de órgãos e tecido não são incomuns $^{(12)}$. É necessário investir em capacitações, bem como no gerenciamento de riscos e na vigilância constante, a fim de aumentar a segurança da assistência ao paciente no processo de doação e transplante de órgãos e tecidos $^{(19)}$.

\section{Biovigilância e estratégias de melhorias para a segurança do paciente}

A biovigilância diz respeito aos aspectos de vigilância, na área da doação e transplantes de órgãos, tecidos e células, envolvendo as ações de monitoramento desde a seleção do doador, a extração, o preparo, o acondicionamento e a distribuição até a realização do enxerto no receptor. Trata-se de um processo que visa obter informações acerca de eventos adversos e prevenir sua ocorrência(24-25). Diversos países, apoiados pela Organização das Nações Unidas (ONU), têm implantado sistemas de biovigilância, como, por exemplo, Itália, Espanha, França, Portugal, Estados Unidos, Austrália, entre outros $^{(24)}$. No Brasil, a instituição do Sistema Nacional de Biovigilância se deu, por meio da Resolução de Diretoria Colegiada (RDC) no 339 em 20 de fevereiro de $2020^{(25)}$, sendo um marco para a segurança do paciente.

Os eventos adversos, após serem notificados, são analisados e transformados em informações que poderão servir de dados, para a atualização e orientação dos profissionais da saúde, visando mitigar riscos, prevenir a ocorrência de novos eventos adversos, melhorar a qualidade dos processos e aumentar a segurança do paciente.

A biovigilância tem papel importante no processo de evidenciar as informações a respeito de eventos adversos ${ }^{(12,19)}$. Por diversas razões, muitas instituições e profissionais ainda resistem em notificar os incidentes e eventos adversos, havendo, inclusive, escassez de publicações evidenciando sua ocorrência. Autores descrevem que, mesmo em contextos de estudos prospectivos de coorte, há dificuldade ao identificar incidentes na área de transplantes, população considerada de risco para potenciais eventos adversos ${ }^{(12)}$.

Em estudo realizado com 4.110 receptores de transplante renal, em que os autores buscaram comprovar o risco de evento adverso relacionado ao uso de medicamentos, os resultados apenas tangem a superfície de potenciais eventos adversos na população de transplantados ${ }^{(12)}$. Entretanto destacam que os dados encontrados, como choque séptico, coma diabético, hipoglicemia, interações medicamentosas, entre outros, são suficientes, para aumentar a preocupação dos profissionais de saúde para com sua prática, além de emergir subsídios que proporcionem o aumento da segurança do paciente ${ }^{(12)}$.

O real número de ocorrências de incidentes e eventos adversos relacionados à doação, ao transplante e à assistência de pacientes transplantados é desconhecido(19-20). Relatórios marcadamente desiguais de ocorrência de incidentes e eventos adversos entre as instituições de transplante sugerem que situações de segurança ainda são subnotificadas ${ }^{(19-20)}$, havendo instituições em que a notificação é zero, 
sugerindo subnotificação substancial de incidentes e eventos adversos.

Em estudo em que foram analisados 438 eventos adversos notificados à Organ Procurement and Transplantation Network (OPTN), no período de um ano, os dados apontaram que $50 \%$ dos eventos notificados provinham de um terço das instituições cadastradas, isto é, a maior parte das instituições ou centros de transplantes não notificou nenhum evento adverso, durante um ano, evidenciando clara subnotificação(20). Tal situação pode estar relacionada ao fato de que a notificação ainda é voluntária(20). A obrigatoriedade da notificação de qualquer evento adverso poderia evidenciar maior número de situações que envolvem a segurança da assistência e, dessa forma, seria possível propor estratégias de contenção de tais eventos.

A notificação permite a disseminação de lições aprendidas, possibilitando a prevenção da recorrência(20). Notificar envolve detalhar o ocorrido e verificar situações de risco e de segurança, elaborando relatórios de análise, após eventos (debriefing) e reforçando que a segurança do paciente é melhorada, quando se melhoram os sistemas e processos de prestação de cuidados ao paciente e se investe em capacitação de pessoas, em vez de culpar indivíduos. A análise $e$ divulgação dos dados de segurança são essenciais, para entender os principais fatores e situações de risco, no intuito de promover a cultura de segurança ${ }^{(20)}$.

Nesse contexto, a taxonomia também é importante tanto no que diz respeito à segurança na comunicação e nos processos, como para a análise de situações de segurança e prevenção de eventos adversos ${ }^{(15,20)}$. A OMS propõe uma taxonomia acerca da segurança do paciente, a qual tem sido amplamente utilizada e seguida por diversos países, ampliando a divulgação de conhecimento acerca do tema(25). Além disso, instituições de relevância têm contribuído de forma significativa para a biovigilância, entre elas, a OMS, a United Network for Organ Sharing (UNOS), a Notify Library, a Anvisa, entre outras.

A UNOS, rede norte-americana que atua como a Organização de Procura de Órgãos (OPO) e o Comitê de Segurança de Processos, tem buscado a integralidade de notificações de incidentes, eventos adversos e quase erros, além de alavancar esses dados, a fim de identificar oportunidades a melhorias no processo, em todo o sistema de doação e transplante(20). O objetivo de se utilizar ferramentas de biovigilância é evidenciar a ocorrência de incidentes e eventos adversos relacionados à segurança, a fim de aumentar a conscientização da importância da vigilância dos processos, encorajar autoavaliações de segurança entre as instituições de transplante e melhorar a segurança do paciente ${ }^{(14,19)}$. A Notify Library, vinculada à OMS, disponibiliza publicações referentes à segurança, no processo de doação e transplante de órgãos e tecidos, permitindo amplo acesso das instituições e profissionais a publicações e relatórios sobre a ocorrência de eventos adversos, riscos potenciais e segurança do paciente.

Ter conhecimento sobre eventos adversos possíveis de acontecer e de que outras equipes e instituições estão experimentando certos tipos de precauções de segurança pode levar a melhorias no sistema, promovendo a autoavaliação dos próprios processos, a análise dos riscos e da suscetibilidade de erros ${ }^{(20)}$. Compartilhar informações que contribuam para a melhoria da segurança dos processos e, por conseguinte, do paciente, é considerada ação de alta prioridade $^{(20)}$.

Dados de segurança também têm sido usados para gerar novas políticas e documentos de orientação(20). Por exemplo, a rede OPTN aprovou política que exige a checagem (check list) de órgão/tecido, no momento do recebimento, para verificar, assim, dados como a ID do doador (código de identificação do doador), qual o órgão, lateralidade (quando há), entre outras informações que o serviço entender necessárias. Além disso, há outros projetos de melhorias que vêm sendo implantados, como o projeto TransNet, que visa mitigar as falhas de transporte de órgãos e tecidos ${ }^{(20)}$.

A análise de eventos adversos ocorridos demonstra que um único incidente de segurança frequentemente ocorre após múltiplos fatores contribuintes. Para melhorar a segurança do paciente, obter diversas perspectivas aumenta a probabilidade de se identificar vulnerabilidades na prestação de cuidados.

A segurança do paciente na assistência à saúde é princípio básico da qualidade do cuidado $^{(12,17,20)}$. Nesse contexto, a literatura aponta estratégias, para aumentar a segurança do paciente, no processo de doação e transplante, como a implementação ou revisão de protocolos $^{(7,12)}$; a realização de estudos sobre boas 
práticas e evidências no cuidado(12); o $^{(12)}$ acompanhamento constante e a análise de fatores indicativos de alterações clínicas, cirúrgicas e de $\operatorname{processos}^{(17)}$; a coleta, análise e acompanhamento de indicadores de qualidade(12); a análise e notificação da ocorrência de incidentes ou eventos adversos ${ }^{(9,15,20)}$; e a contínua capacitação de profissionais ${ }^{(12,20)}$.

Assim, a divulgação de eventos adversos ocorridos e de medidas de mitigação de danos, na comunidade científica, visa promover amplo conhecimento de situações que possam ocorrer e, dessa forma, criar estratégias para evitar sua ocorrência ou recorrência(20). Ratifica-se, assim, a importância da biovigilância e da busca contínua por melhores práticas e maior segurança do paciente $\mathrm{p}^{(12,19,20)}$.

\section{CONCLUSÃO}

Os eventos adversos relacionados ao processo de doação e ao uso terapêutico de tecidos e órgãos humanos para transplantes identificados na realização deste estudo compreendem complicações cirúrgicas e vasculares, eventos relacionados à administração de medicamentos, a reinternações ou ao aumento do tempo de hospitalização, a infecções, à malignidade, à perda do enxerto, à queda e ao óbito. Da mesma forma, foram identificadas falhas em processos implicando risco de ocorrência de eventos adversos, como: falhas na comunicação ou em registros dos profissionais da saúde; falha em dispositivos e equipamentos de saúde; falha referente aos processos que envolvem medicamentos, como preparo, administração e prescrição; falhas no processo de doação e transplante, como falhas na alocação de órgãos, na identificação do doador e no acondicionamento e transporte do órgão ou tecido doado; falta de conhecimento ou não seguimento de rotinas e protocolos préestabelecidos; e falha na transição do cuidado.

As ações de biovigilância e as estratégias, para reduzir riscos e ocorrências de eventos adversos no processo de doação e transplante de tecidos e órgãos identificados neste estudo, englobam: a importância da assistência ao paciente ser realizada de forma interdisciplinar; a capacitação contínua dos profissionais, assim como o dimensionamento adequado da equipe assistencial; a implantação ou mesmo a revisão de protocolos; a profilaxia de eventos adversos; a implantação e seguimento de sistema de biovigilância com notificação, análise e disseminação de dados, visando à promoção de segurança e à diminuição de ocorrência ou recorrência de eventos adversos.

Quanto às contribuições para a área de enfermagem, os resultados apresentados permitem maior conhecimento acerca da temática de estudo, fornecendo subsídios para maior segurança ao processo de doação e uso terapêutico de tecidos e órgãos humanos para transplante, processo em que se enfatiza o papel do enfermeiro, enquanto profissional que atua nas diferentes etapas da doação e do transplante.

É importante destacar que as conclusões apresentadas por este estudo não podem ser generalizadas, pois os artigos incluídos nesta revisão integrativa da literatura enumeraram investigações cuja maioria das evidências foi estabelecida no nível IV. Essas evidências são consideradas menos robustas e carentes de estratégias metodológicas que contemplem a síntese das melhores evidências científicas, ou seja, oriundas de revisões sistemáticas ou de ensaios clínicos randomizados.

Sugerem-se novos estudos que possam identificar e analisar riscos, eventos adversos e, principalmente, ações para diminuir os riscos e aumentar a segurança e qualidade no processo de doação e transplante de órgãos e tecidos.

\section{REFERÊNCIAS}

1 - Brasil. Ministério da Saúde. Documento de referência para o Programa Nacional de Segurança do Paciente. Brasília: Ministério da Saúde; 2014.

2 - World Health Organization (WHO). World Alliance for Patient Safety Forward Programme 2008-2009. Geneva: World Health Organization; 2010.

3 - Brasil. Ministério da Saúde. Manual de biovigilância de células, tecidos e órgãos humanos. Brasília: Anvisa; 2021.

4 - Singh K, Kim SJ. Epidemiology of kidney discard from expanded criteria donors undergoing donation after circulatory death. Clin J Am Soc Nephrol. 2016;11(2):317-23. DOI: 10.2215/CJN.07190715

5 - Borgnia D, Dip M, Cervio G, Martinitto R, Halac E, Aredes D, et al. Sistema de análisis de eventos adversos aplicado a pacientes 
trasplantados hepáticos. Med Infant. 2018 [citado em 15 mar 2021]; 25(1):32-7. Acesso em: https://pesquisa.bvsalud.org/portal/resource/es/b iblio-883482

6 - Cartana JB, Breier A, Anelo T. Analysis of healthcare-related incidents in the city of Porto Alegre, Rio Grande do Sul, between 2016 and 2017. Vigil Sanit Debate 2020;8(1):71-9. DOI: 10.22239/2317-269x.01315

7 - Espindola S, Nascimento KC, Knihs NS, Alvarez AG, Sebold LF, Paim SMS. Intraoperative patient safety during liver transplantation: Integrative review. Acta Paul Enferm. 2020;33:eAPE20180187. DOI: 10.37689/actaape/2020AR0187

8 - Siqueira MM, Araujo CA, Roza BA, Schirmer J. Indicadores de eficiência no processo de doação e transplante de órgãos: Revisão sistemática da literatura. Rev Panam Salud Publica 2016 [citado em 15 mar 2021]; 40(2):90-7. Disponível em: https://www.scielosp.org/pdf/rpsp/2016.v40n2/9 $\underline{0-97}$

9 - Bahrami A, Khaleghi E, Vakilzadeh AK, Afzalaghaee $M$. Process and barriers to organ donation and causes of brain death in northeast of Iran. Electron Physician. 2017;9(2):3797-3802. DOI: $\underline{10.19082 / 3797}$

10 - Mendes KDS, Silveira RCCP, Galvão CM. Revisão integrativa: Método de pesquisa para a incorporação de evidências na saúde e na enfermagem. Texto \& Contexto Enferm. 2008;17(4):758-64. DOI: 10.1590/S0104$\underline{07072008000400018}$

11 - Oxford Centre for Evidence-based Medicine. Levels of Evidence Working Group. Oxford: CEBM; 2011.

12 - Pontes L, Silva SR, Lima AP, Sandri LCS, Batistela AP, Danski MTR. Incidents related to the Hickman ${ }^{\circledR}$ catheter: Identification of damages. Rev Bras Enferm. 2018;71(4):1915-20. DOI: 10.1590/0034-7167-2017-0051

13 - Grossi PA, Gasperina DD, Lombardi D, Ricci A, Piccolo G, Costa AN. Organ transplantation from "increased infectious risk donors": The experience of the Nord Italia Transplant program - a retrospective study. Transplant Int. 2018;31(2):212-9. DOI: 10.1111/tri.13086
14 - Rosa LP, Ventura L, Kadishari S, Duarte M, Adam Netto A. Evaluation of knowledge of physicians with specialty in medical clinic and surgical clinic about the process of corneas donation. Rev Bras Oftalmol. 2017;76(2):74-80. DOI: $\underline{10.5935 / 0034-7280.20170015}$

15 - Cristelli MP, Ferreira A, Hannun P, Felipe C, Aguiar W, Franco M, et al. De novo everolimus for recipients of kidney transplants from HLA identical donors. J Bras Nefrol. 2016;38(2):225-33. DOI: 10.5935/0101-2800.20160032

16 - Lima LF, Martins BC, Oliveira FR, Cavalcante RM, Magalhães VP, Firmino $P Y$, et al. Pharmaceutical orientation at hospital discharge of transplant patients: Strategy for patient safety. Einstein 2016;14(3):359-65. DOI: 10.1590/S167945082016A03481

17 - Meng H, Yang J, Yan L. Donor safety in adultadult living donor liver transplantation: A singlecenter experience of 356 cases. Med Sci Monit. 2016;22:1623-9. DOI: 10.12659/MSM.898440

18 - Ribeiro MPA, Sandes-Freitas TV, Sato KH, Ribeiro Junior MA, Silva-Junior HT, MedinaPestana JO. Effect of induction therapy in kidney transplantation in sensitive patients: analysis of risks and benefits. J Bras Nefrol. 2016;38(1):82-9. DOI: $10.5935 / 0101-2800.20160013$

19 - Czerwiński J, Kaliciński P, Danielewicz R. Serious adverse events and reactions in organ transplantation; a web-net tool-based nationwide system for reporting and monitoring. Ann Transplant. 2015;20:243-8. DOI: 10.12659/AOT.893009

20 - Stewart DE, Tlusty SM, Taylor KH, Brown RS, Neil HN, Klassen DK, et al. Trends and patterns in reporting of patient safety situations in transplantation. Am J Transplant. 2015;15(12):3123-33. DOI: 10.1111/ajt.13528

21 - Weir MR, Gravens-Muller L, Costa N, Ivanova A, Manitpisitkul W, Bostom AG, et al. Safety events in kidney transplant recipients: Results from the folic acid for vascular outcome reduction in transplant (FAVORIT) trial. Transplantation 2015;99(5):1003-8.

DOI:

\subsection{7/TP.0000000000000454}

22 - Florman S, Becker T, Bresnahan B, ChevaileRamos A, Carvalho D, Grannas G, et al. Efficacy 
12| Treviso P, Schirmer J, Mendes KDS, et al.

and safety outcomes of extended criteria donor kidneys by subtype: Subgroup analysis of BENEFITEXT at 7 years after transplant. Am J Transplant. 2016;17(1):180-90. DOI: 10.1111/ajt.13886

23 - Moassesfar S, Masharani U, Frassetto LA, Szot GL, Tavakol M, Stock PG, et al. A comparative analysis of the safety, efficacy, and cost of islet versus pancreas transplantation in nonuremic patients with type 1 diabetes. Am J Transplant. 2016;16(2):518-26. DOI: 10.1111/ajt.13536

24 - Roza BA, Kusahara D, Pessoa J, Treviso P, Oliveira $P$, Leite $R$, et al. Biovigilance and transplantation models and initiatives: A narrative review. Vigil Sanit Debate 2019;7(4):10-16. DOI: 10.22239/2317-269x.01403

25 - Brasil. Ministério da Saúde. Resolução de Diretoria Colegiada - RDC no 339, de 20 de fevereiro de 2020. Dispõe sobre a instituição do Sistema Nacional de Biovigilância. Diário Oficial da União 2020;38:72.

\section{Editores Responsáveis:}

Juliana Dias Reis Pessalácia

Helisamra Mota Guedes

Nota: Não houve financiamento por agência de fomento.

Recebido em: 14/10/2020

Aprovado em: 26/04/2021 